\title{
MOBILE PROCESS SUPPORT SYSTEMS
}

\author{
Experiences from a case study
}

\author{
Børge Haugset \\ SINTEF ICT, borge.haugset@sintef.no
}

\begin{abstract}
Work process support systems, both in the form of workflow systems and of more loosely structured systems have been widely developed and also to a large extent been taken into use in a large number of work situations. As computing is becoming both pervasive and nomadic, workers use of computing and communication services is less limited to solitary moments at an office desk. Thus it gets more and more important to provide mobile work process support systems. This paper presents experiences related to the development, introduction and evolution of such systems through results from a case study following phone engineers. The main conclusions from the study are that that smaller terminals not necessarily does the job better, computerised systems are not always better than paper-based systems, and that supporting nomadic work must be done in agreement with the overall work context.
\end{abstract}

Key words: Mobile Information systems applications in organizations; Interdependencies of mobile information technologies and organizational structures

\section{INTRODUCTION}

A larger proportion of work is today done by what is termed the symbolic analyst (Thomson and Warhurst, 1998), whose work resources and work products are primarily symbol-structures. The proportion of such work is predicted to increase in the years to come, based on profound changes in business environments in connection to knowledge intensity, globalisation, and virtualisation. The main work pattern of the symbolic analysts is knowledge intensive projects often in dynamically networked organizations. Knowledge work, which is inherently cognitive rather than physical (Davis, 2002) will not be tied to the office only, but will consist of continuous collaboration, communication, and co-ordination on the fly among 
distributed actors (Bellotti and Bly, 1996; Luff and Heath, 1998). The modern knowledge worker works from many different locations (home, in the clients office, on a plane), using a variety of information processing devices based on what is available and practical at the time, including stationary PCs connected to a LAN or WLAN, portable PCs, and personal information appliances (PIA) including mobile phone and PDAs connected wirelessly to the network.

To address the needs of these types of workers (and of other workers whose work situation is inherently mobile), a number of solutions to mobile process support has been developed over the last years. Based on the visions of the impact of anytime/anyplace computing on increased productivity, one would expect these process support systems to already have had immense impact, and that even more revolutionary changes is to be expected as the $3 \mathrm{G}$ infrastructure (eventually) will be put into broad-scale operation.

Based on following the development, introduction and take-up of this type of system over a number of years in different organizational settings, we have found that rather than dramatically changing the organizations taking these kinds of systems into use, the changes in work practice seem to be more gradual and evolutionary.

We will in this paper present some of the overall findings from a casestudy on the development, introduction and use of a mobile work process support solution. In the next section we present the case. Section 3 summarizes the main learning from the case study, whereas section 4 concludes the article with views for further work in this area.

\section{DESCRIPTION OF CASE STUDY}

The results presented in this paper are collected on the basis of a casestudy within work-process support for phone-engineers (Haugset, 2001).

In this case study, the researcher was doing a field study covering the introduction of two new mobile process support systems in a large telecommunications company in Norway. The study included interviews with engineers, their managers, and people working at the service centre, and following and observing the engineers as they were performing their task with support of the different systems.

According to Benbasat, Goldstein, and Mead (1987), a case study is an approach well suited when the context of investigation takes place over time, is a complex process involving multiple actors, and is influenced by events that happen unexpectedly. Our case satisfies these criteria. In deciding whether to use case studies or not, Yin (1994) encourages to evaluate the type of research question, the control the investigator has over the actual 
behavioural events, and how the case focuses on contemporary as opposed to historical events.

Yin (1994) states that the relevance of a single case study is high when the goal is to identify new and previously not researched issues, but when the intent is to build and test a theory, a multiple case study should be designed. At the start of the study there had not been reported much research within this area earlier, and a single case approach was chosen. Time and resource constraints also made this the most viable method.

The first interviews done were quite open, to get a broad understanding of the context of work. As for the later interviews and observations, these were more focused. The researcher observed, during 18 months, 6 engineers at work, each observation ranging from two hours to a full day. Furthermore, several phone interviews with engineers and interviews with other staff in the company were made. Based on this, a qualitative analysis was performed. Rather than making broad generalizations, the aim with the study was to pinpoint some factors that engineers think are important for performing their work. More in-depth studies should be performed in order to further generalize and support these findings.

A phone engineer is a common term used for those installing and maintaining the telecommunication network all the way to the end-user. The case-study focused on engineers delivering solutions to end-users and correcting errors. The work processes for these groups of tasks follow a similar overall pattern with or without a mobile work process support system. They need to establish or mend a line somewhere on the way to the customers' telephone outlet. They need information about where to go and what kind of job to expect. Occasionally they also need help from others, either from a service centre, or by other engineers.

The basis of each task is a work order which should contain all necessary information to perform the work. We followed the introduction and use of several mobile systems for following up work-orders, a previously paperbased process. The first system (Dart) was based on using a handheld device (introduced originally in 1998), whereas in the second one (Advantex), one used a portable computer that was placed in the engineers car (Haugset, 2001). Advantex was introduced in 2000 , and a picture of a car with the Advantex system installed is shown in figure 1. The old paper-based work orders contained the same information that could be accessed by Dart and Advantex.

For paper-orders, the overall flow was as follows: A customer reported an order or an error to customer service, which forwarded this to the servicecentre. The service-centre performed line-checks centrally, and established work orders for tasks that couldn't be done centrally. Each day, the engineers collected work orders (on paper) by going to the service centres. After each 
task was completed this was reported to the service centre before starting on the next task. This was done calling the centre on a mobile phone. The centre was also called for assistance, e.g. to perform line checks. The service centre performed final treatment of the order after it was reported fixed, billing the customer for the performed job.

In Dart, the major change was the all work orders were stored in a database, each task assigned to one of the engineers. At the start of the workday, the engineer downloaded the work order and all the information about the task to his personal work tool, using their mobile phones as modems. The tasks were structured as HTML files, and accessed by an HTML viewer on the PDA. When a task was finished, the engineer was to report the job directly to the database by using the PDA. The people at the service centre also accessed this database.

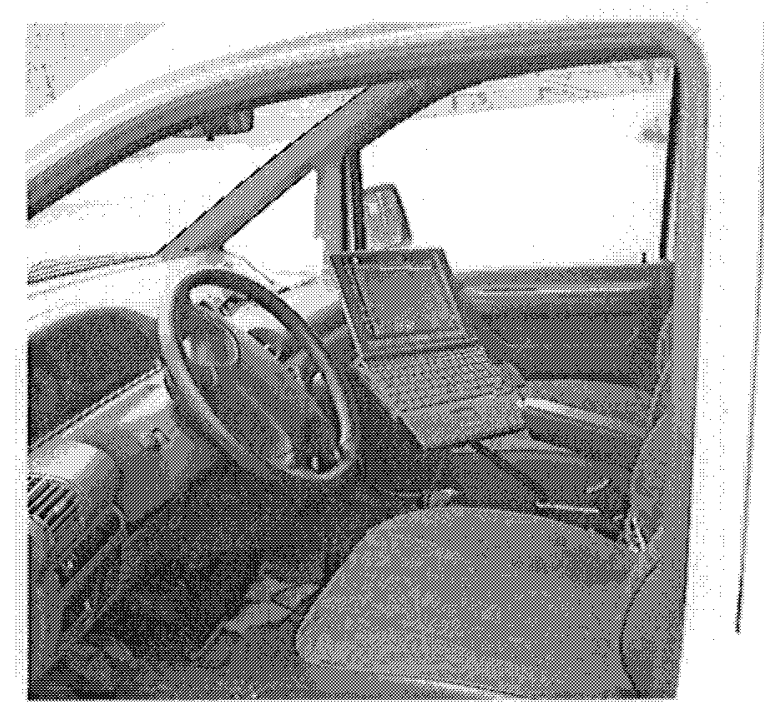

Figure 1. A car with Advantex running on a laptop

When using Advantex the work flow was almost the same as in Dart. However, Advantex demanded a more interactive use. The engineer had to press a button to mark when he started working, when he got to the customer, and when he finished each job. A resource centre always knew where the different engineers are, and if an important fix in the network was needed, the engineer closest to the site could be dispatched to the site.

Common to both Dart and Advantex was that the engineer would no longer have to go to a central in the morning to pick up his work list; he could drive straight to the first job. 


\section{INSIGHTS AND LEARNINGS}

Based on the knowledge gained from the field study, we now present some factors that are worth focusing on when introducing mobile work process support:

\subsection{Smaller and more portable is not always better}

One would easily be led to believe that a PDA containing all information on the work would result in satisfied engineers. They had access to up-todate information at all times, without having to print out the tasks. In reality, however, this was not the case. The actual work flow for Dart turned out to be quite different from the intended flow.

Even if they are doing mobile work proper (moving around is an important part of their work, being both travelling and wandering (Kristoffersen \& Ljungberg, 2000)), a higher degree of satisfaction was reported on the Advantex system where they used laptops situated in their cars. The dissatisfactions with the Dart system were many and important, leading to a different work ritual than initially envisioned. A small screen and tiny keyboard buttons combined with a slow processing speed and shortlived batteries on the PDA resulted in few people using it. Furthermore, the use of a mobile phone as a modem to upload and download work was tedious and unstable, often disconnecting so you had to try it again. As a result, some people downloaded all of the days work while having their breakfast, and uploaded the complete finished jobs. They chose to take their work home instead of using the Dart system as intended. A lot of people chose to call the service centre to describe their finished work, as they had done during the paper-based work situation. The time-consuming use of the PDA was seen as extra work they didn't see the usefulness of.

In Advantex, many of the problems of Dart were gone. Instead of a slow PDA they had access to a laptop. The laptops had their own modem, reducing the clutter with the mobile phone. As the laptop had more processing power than the PDA, the system only needed to send the data to and from the database, instead of the complete layout. The rendering of the data was done on the laptop in a graphical user interface. This reduced the time spent on downloading and uploading work.

The engineers' responsibilities were also enhanced, allowing engineers direct access to the database.

The larger machines were found to have more advantages than disadvantages, with better keyboard, faster processing, larger displays making it easier to have an overview of the different work-orders etc. This result was also linked to the next point: 


\subsection{Computerised is not necessarily better than paper- based}

The case is an example of going from a paper-supported to a computersupported process. For this to be efficient, the advantages of the new medium must be larger than the advantages of the old. Some problems related to the use of the system within the work environment were witnessed in the first system (Dart). The terminals did not work in cold and rain. Both in connection to this system and the version based on a portable PC, paper were still used a lot, even if it was explicitly discouraged due to security reasons. The workers used the traditional paper orders in a very flexible manner, jotting down additional information as they went along, and found this more flexible and surveyable than to input this on the PDAs. The engineers preferred copying notes from the Advantex laptop to a sheet of paper to bring into the customers building instead of bringing the H/PC inside. This is an example of the advantages regarding the micro-mobility of paper; paper is easy to use in many contexts and across contexts when necessary (Luff \& Heath, 1998). Since the data collected as part of doing the job was normally only of interest to the engineer before reporting the job, it was sufficient for the overall organization that this was entered after the job was finished.

\subsection{To support mobile knowledge work it is not sufficient to support the nomadic part of the work}

At one of the service centres studied, in the original paper-based work process, the engineers met each morning at the main office to get their assignments before driving off to the different tasks. With the introduction of the computer-supported systems, this overall process was supposed to change. The engineers were meant to download their work assignments for the day from home, and drive straight to the first job. They were in fact explicitly forbidden to go to the office in the morning.

Most of the engineers, however, decided to meet half an hour before work usually started, some also met for lunch. In the meetings they sat down with a cup of coffee and a cigarette, and chatted about issues ranging from the prices of gasoline to today's work. They felt that they had a joint need in upholding this arena, regardless of the rules. Many engineers said they knew co-workers who were better in some fields than others, and they often called them if they got stuck on something. The community of practice (Wenger, 1998) supported by these meetings allowed for overhearing and joining colleagues' conversations, regarded as important in the learning process 
(Bellotti and Bly, 1996). The nomadic part of the work, driving around in the city to install and fix telecom installations, was made easier by meeting in informal meetings, drawing on each others' experiences and practices.

The joint meetings also gave a larger visibility of the knowledge that the experts had, and thus higher self-esteem and pride in the job. One worker said "You talk about your profession; you get something to be proud of." This resembles what Orr describes as people telling each others war stories (Orr, 1996). As a phone engineer, being good is about showing skill. At the same time you teach the others what you have learnt.

The company had created a virtual meeting place on the Intranet, where engineers could ask questions and discuss issues with colleagues. At the time of the study very few people used this service. When asked why, one engineer thought it was because it was something completely different from asking a knowledgeable colleague a question while he is sitting beside you: On the Intranet you had to decide that "Today I'll sit down and tell others about my experiences". The implicit communication at meetings had been suggested replaced by an explicit form of communication through the Intranet.

\section{SUMMARY AND FURTHER WORK}

This paper summarises some of the learning from following the development, introduction and evolution of a mobile work process support solution. It highlights that it is difficult to develop generic solutions within this area, and that such systems must fit the needs and characteristics of those using them. Further studies of similar introductions will enhance the value of the findings.

Our approach for future work within this problem-area will, in particular, be directed to the support of emergent non-routine work-processes, where systems supporting these tasks have unclear, inconsistent, and unstable user requirements, and where they can benefit to be accessible on a number of platforms. Traditional enterprise systems tend to be quite inflexible, hardly adaptable at runtime, and primarily support routine processes. Existing workflow management systems have typically been focused on dealing with exceptions and have thus offered some support for adaptive processes (Klein, 1998). These types of systems, however, have typically overlooked emergent processes, which seem to encompass an increasing part of knowledge workers' activities. On the other hand, only supporting the emergent work style of the individual is at times inefficient, because routine parts of the work can be prescribed and automated, and because sharing of explicitly defined work processes facilitates co-ordination, collaboration and 
communication between multiple parties. Thus there is a need for a balance between prescription and emergent representations.

\section{REFERENCES}

Bellotti, V. and Bly S. (1996): Walking away from the desktop Computer: Distributed collaboration and mobility in a product design team. Proceedings of the $C S C W^{\prime} 96$, Cambridge, MA, 1996, 209-218.

Benbasat, I., Goldstein, D. K. and Mead, M. (1987) "The case research strategy in studies of information systems" MIS Quarterly (11:3) p 369-386

Davis, G (2002): Anytime/Anyplace Computing and the Future of Knowledge Work. Communications of the ACM 45 (12).

Haugset, B. (2001): Montoren og Terminalen (The Phone Engineer and the Terminal, in Norwegian) M.Sc. Thesis, University of Oslo.

Klein, M. (1998) Workshop: Towards Adaptive Workflow Systems, CSCW-98, Seattle. Available on the Web at http://ccs.mit.edu/klein/cscw-ws.html 20040526.

Kristiansen, S. \& Ljungberg, F. (2000). Mobility - From stationary to mobile work. In: Braa, K., Sørensen, C., \& Dahlbom, B. (Eds.) Planet Internet, Studentlitteratur, Lund.

Luff, P. \& Heath, C. (1998). Mobility in collaboration. In: Proceedings of the CSCW-98, Seattle, USA, 305-314

Orr, J. E. (1996) Talking about Machines: an Ethnography of a Modern Job. Cornell University Press

Thompson, P. \& Warhurst, C. (1998). Workplaces of the Future. Macmillan Business

Wenger, E. (1998) Communities of Practice: Learning, Meaning, and Identity. Cambridge University Press.

Yin. R. (1994) Case study Research, 2nd ed. SAGE Publications. 